DOI: 10.17117/na.2015.11.04.037

Поступила (Received): 22.11.2015

\title{
Бондарь С.C.
}

\section{Оценка уровня неспецифических адаптационных} реакций методом активной радиометрии

\author{
Bondar S.S. \\ Assessment of the level of nonspecific adaptive \\ reactions method of active radiometry
}

В исследовании обсуждается возможность оценки уровня неспецифической реактивности организма на фоне острого инфекционно-воспалительного процесса методом активной радиометрии. Показано, что уровень неспецифической адаптации существенно изменяется в динамике заболевания. Метод активной радиометрии является чувствительным к изменению показателя адаптации и может быть использован для мониторинга неспецифических адаптационных реакций

Ключевые слова: активная радиометрия, неспецифический адаптационный синдром, стресс, диагностика, пневмония

\section{Бондарь Станислав Станиславович}

Заведующий лабораторией

Тульский государственный университет г. Тула, ул. Смидович, 12
The study discusses the possibility of assessing the level of nonspecific reactivity of the organism on the background of acute infectious inflammatory process by the method of active radiometry. Method of active radiometry can be used to monitor nonspecific adaptive reactions

Key words: active radiometry, non-specific adaptation syndrome, stress, diagnosis, pneumonia

\author{
Bondar Stanislav Stanislavovich \\ Head of Laboratory \\ Tula state university \\ Tula, Smidovich st., 12
}

В 90-е годы XX века учеными Саратовского филиала института радиотехники и электроники РАН было обнаружено явление объемного резонансно-волнового состояния молекулярной системы воды и водной компоненты биосреды организма в крайневысокочастотном (КВЧ) и сверхвысокочастотном (СВЧ) диапазоне частот электромагнитных излучений $[1,2]$. С этим явлением связано открытие частот собственных молекулярных колебаний воды, которые выполняют в организме коммуникационно-корректирующую роль, составляя совместно с нейрогуморальной регуляцией единую систему управления жизнедеятельностью организма [1-3].

Возможности современных радиоэлектронных технологий позволяющие регистрировать слабые собственные электромагнитные колебания, на частотах молекулярных колебаний водной компоненты, позволили создать новый диагностический метод оценки функционального состояния биотканей - активную 
радиометрию (АР) $[3,4]$. Результаты проведенных исследований показали чувствительность АР к изменениям транскапиллярного обмена воды в тканях [59]. Так же показана возможность применения АР в диагностике острой воспалительной патологии внутренних органов и мониторинге патологических изменений в процессе лечения [10-27].

Цель исследования - изучение возможностей оценки адаптационных реакций у пациентов с инфекциями нижних отделов респираторного тракта методом АР.

Материалы и методы. На клинической базе кафедры терапии Саратовского военно-медицинского института, 8 ГКБ (г.Саратов), ГБУЗ КО «ЦРБ Бабынинского района» (Калужская область) под контролем локального этического комитета Тульского государственного университета в соответствии с требованиями Хельсинской декларации, в период с 2009 по 2014 г. проведено проспективное, контролируемое двойное слепое клиническое исследование. При этом методом АР обследовано 200 пациентов мужского пола в возрасте 19-30 лет с острой воспалительной патологией нижних отделов дыхательных путей (ОВДП).

Группа пациентов с верифицированным диагнозом ОВДП состояла из подгруппы пациентов $(\mathrm{n}=120)$ с внебольничной пневмонией (ВП), и пациентов (n=80) с острым необструктивным бронхитом (ОБ). Группа контроля состояла из 80 практически здоровых лиц мужского пола, средний возраст которых составил $25 \pm 5$ лет.

АР проводилась с помощью радиоэлектронного комплекса - «Аквафон» (регистрационное удостоверение ФСР 2010/07292) и АР осуществлялась путем ручного перемещения приемно-излучающего модуля комплекса по кожной поверхности грудной клетки $[3,4]$. В качестве критерия оценки интегральной резонансно-волновой активности водосодержащих сред организма, используется показатель «волновая активность» - ВА, представляющий собой сумму амплитуд радиоизлучения, зарегистрированного с каждой точки обследуемой поверхности, характеризующих суммарную активность резонансно-волновых процессов тканей.

Для сравнительной оценки состояния резонансно-волнового состояния водной компоненты биосреды в разных анатомо-топографических областях использовались средние значения амплитуды радиосигнала, регистрируемого с поверхности тела в проекции этих областей. Данный показатель в тексте обозначен как «радиоотклик» - РО. Оценку функционального состояния организма проводили с использованием индекса адаптации [27].

Статистический анализ результатов исследования проводился с помощью программы Statistica 6.0. Применению параметрических статистических методик предшествовала проверка распределения экспериментальных наблюдений в группах исследования на соответствие нормальному закону распределения с использованием критерия Шапиро-Уилка. Оценку диагностической информативности исследованных показателей проводили с использованием ROCанализа. 
Результаты и их обсуждение. Результаты проведенного исследования свидетельствуют о том, что у здоровых лиц величина средние значения показателя ВА составляет 4223,3 ед. (95\% ДИ 4123,1-4324,6), РО 97,3 ед. (95\% ДИ 95,2-100,1). В группе пациентов с ОВДП средние значения показателя ВА составили 5314,1 ед. (95\% ДИ 4991,3-5437,5), РО 119 ед. (95\% ДИ 110,8-145,9 ед.). Анализ информативности показателя ВА в выявлении воспалительных изменений, проводимый путем оценки площади под ROC - кривой, составившей 0,91 ед., при 95\% ДИ от 0,83 до 0,99. Для критерия максимальной мощности (чувствительность 87,0\%; специфичность 97,0\%) точкой разделения будет являться значение ВА 4310 ед. При этом отношение правдоподобия (ОП) положительного результата теста составило 10,0 отрицательного результата теста - 9,8.

Динамика ИА и РО на стороне поражения входе лечения ВП представлена на рисунке.

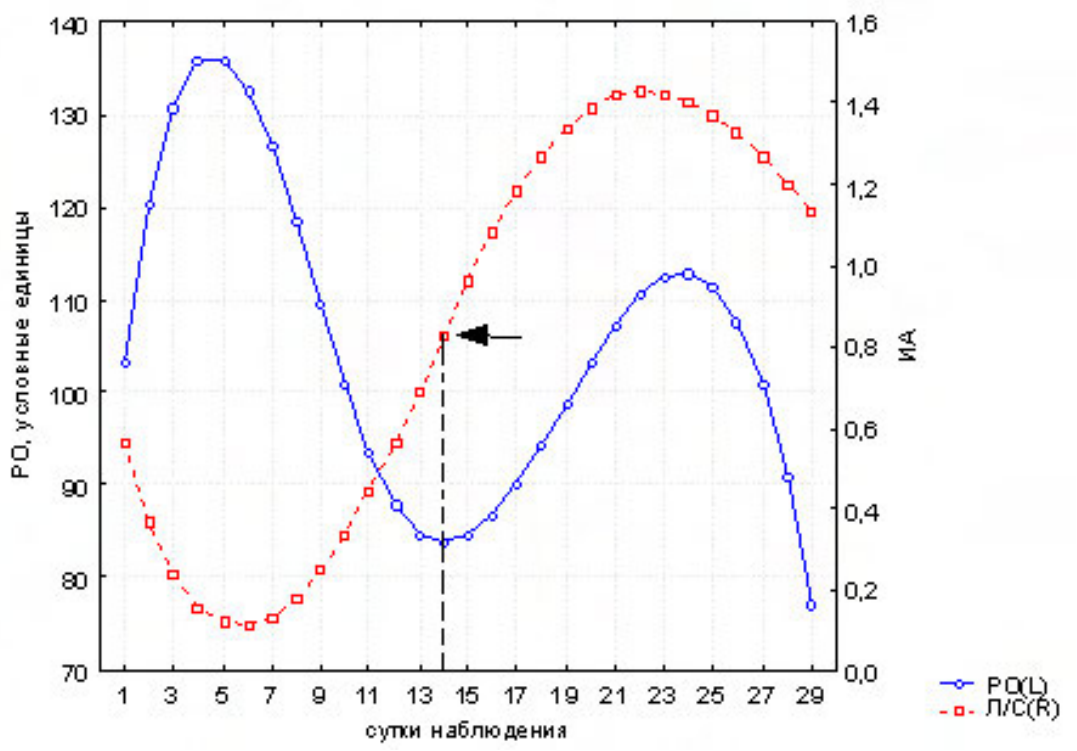

Рис. 1.Динамика изучаемых показателей в прочессе лечения

Результаты проведенного исследования выявили колебательный характер динамики ИА и ВА. При этом динамика ВА характеризуется тремя экстремумами за период наблюдения (4-5; $13-15 ; 23-25$ сутки ВП). При этом минимум ВА, регистрируемый на 14 сутки, приходится на значение индекса адаптации 0,8 ед., и делит график зависимости $\mathrm{f}=\mathrm{hA}(\mathrm{t})$ на две симметричные части (отмечено стрелкой).

Проведенный анализ динамики исследованных маркеров патологического процесса показал, что первая неделя заболевания характеризуется снижением ИА с исходного уровня 0,56 ед., соответствующего реакции спокойной активации, до 0,1 ед., указывающего на развитие острой стресс-реакции. В указанный период имеет место повышение РО со 103 до 134 ед. Вторая неделя ВП характеризовалась увеличением значений ИА, который к 12-м суткам заболевания достигает исходных 0,56 ед. В это же время отмечалось снижение абсолютных значений ВА, к 12-м суткам до 87 ед. Далее, к 15-м суткам ВП, ИА достигал 
0,96 ед., соответствуя стадии повышенной активации. К этому моменту фиксировался абсолютный минимум значений РО, составляющий 84 ед. При этом ИА продолжая увеличиваться, к 22 суткам достигал своего максимума - 1,43 ед., указывая на выраженную активацию неспецифических адаптационных реакций. Абсолютный максимум ИА совпадал по времени с локальным максимумом значений РО - 110 ед. Далее, вплоть до 28 суток заболевания, ИА продолжая снижаться, достигал к окончанию лечения 1,23 ед., свидетельствуя о незавершенности процессов восстановления. К этому времени отмечался абсолютный минимум РО (77 ед.).

Анализируя информативность РО в оценке неспецифической резистентности, было установлено, что его точность составляет 94,6\% (в диапазоне 84$100 \%)$. Исследуя координаты полученной для данного критерия характеристической кривой, была определена точка разделения, обеспечивающая максимальную мощность (чувствительности) оценки, в которой значение РО составляет 116 ед. (чувствительность 100\%, специфичность - 87,5\%). Таким образом, значения РО, превышающие указанные, с высокой степенью надежности будут свидетельствовать о состоянии острого стресса.

Полученные в настоящем исследовании результаты позволяют считать перспективным дальнейшее изучение диагностических и прогностических возможностей активной радиометрии, обеспечивающей возможность оперативной оценки функционального состояния тканей в динамике заболевания.

При этом активная радиометрия позволяет идентифицировать и отслеживать патологические процессы, сопровождающиеся изменениями транскапиллярного обмена в тканях, т.е. осуществлять оценку метаболического статуса тканей в динамике заболевания $[25,26]$. Это свойство метода может быть полезно в оценке состояния миокарда у больных инфекциями респираторного тракта.

Выводы:

1. На модели острого воспалительного процесса нижних отделов респираторного тракта показана тесная связь интенсивности собственного радиоизлучения водных сред с патологическим процессом у пациентов с инфекциями респираторного тракта.

2. АР позволяет обеспечивать мониторинг адаптационных реакций у пациентов с ВП.

\section{Список используемых источников:}

1. Бецкий О.В. Пионерские работы по миллиметровой электромагнитной биологии, выполненные в ИРЭ РАН //Биомедицинские технологии и радиоэлектроника. 2003. №8. С. 11-20.

2. Петросян В.И. Резонансное излучение воды в радиодиапазоне // Письма в ЖТФ. 2005. Т. 31. Вып. 23.

C. 29-33.

3. Еськов В.М. и др. Избранные технологии диагностики: Монография. Тула: ИНФРА, 2008. 296 с.

4. Терехов И.В. Транс-резонансная функциональная топография в диагностике заболеваний органов дыхания (новый метод обработки информации). Автореф. дисс. канд. мед. наук, Тула, 2007. $24 c$.

5. Терехов И.В. Оценка сосудистой проницаемости с помощью активной радиометрии //

Аспирантский вестник Поволжья. 2009. №7-8. С.187-190. 
6. Терехов И.В., Солодухин К.А., Аржников В.В. и др. Возможность использования активной СВЧрадиометрии для оценки альвеолярно-капиллярной проницаемости в эксперименте // Регионарное кровообращение и микроциркулящия. 2011. № 4. С. 83-86.

7. Громов М.С., Терехов И.В., Бондарь С.С. и др. Исследование состояния транскапиллярного обмена и его коррекция с помощью радиоэлектронного лечебно-диагностического комплекса «Аквафон» // Биомедицинская радиоэлектроника. 2010. № 3. С.43-48.

8. Громов М.С., Терехов И.В., Бондарь С.С. и др. Технология оценки проницаемости капилляров с помощью активной радиометрии // Вестник новых медицинских технологий. 2010. T.17. № 1. C.135-137.

9. Терехов И.В., Дзюба М.А., Бондарь С.С. и др. Оценка альвеолярно-капиллярных нарушений при развитии тяжелого гемодинамического отека легких у крыс и его коррекция с помощью СВЧ излучения // Саратовский научно-медицинский журнал. 2011. Т. 7. № 2. С. 389-392.

10. Терехов И.В., Петросян В.И., Громов М.С. и др. Дифференциальная диагностика заболеваний грудной клетки с помощью Транс-резонансной функциональной топографии // Вестник медицинского института "РЕАВИЗ": реабилитация, врач и здоровье. 2013. № 3 (11). С. 18-26.

11. Аржников В.В., Лифшиц В.Б., Парфенюк В.К. и др. Интегральная оценка воспалительного процесса у больных внебольничной пневмонией методом активной радиометрии // Саратовский научномедицинский журнал. 2011. Т.7. № 4. С. 817-822.

12. Терехов И.В., Петросян В.И., Громов М.С. и др. Технология динамической оценки воспалительного процесса с помощью активной резонансной радиометрии // Вестник новых медицинских технологий. 2010. T.17. № 1. C.135-137.

13. Терехов И.В., Громов М.С., Парфенюк В.К. и др. Применение метода ТРФ-топографии в диагностике воспалительных изменений нижних отделов респираторного тракта // Саратовский научномедицинский журнал. 2008. T.4. № 1. С. 79-83.

14. Терехов И.В., Солодухин К.А., Никифоров В.С. и др. Использование радиоволнового зондирования водосодержащих сред для оценки функционального состояния миокарда у больных с артериальной гипертензией // Российский кардиологический журнал. 2013. №5 (103). С.40-43.

15. Лобаков А.И., Громов М.С., Дубовицкий С.А. и др. Применение транс-резонансной функциональной топографии с целью оптимизации диагностической тактики у пациентов с подозрением на острый панкреатит и его осложнения // Хирург. 2008. № 8. С. 22-33.

16. Громов М.С., Масляков В.В., Брызгунов А.В. и др. Трансрезонансная функциональная топография 8 оптимизации диагностики у пациентов с подозрением на острую воспалительную патологию органов брюшной полости // Анналы хирургии. 2008. №6. С. 60-64.

17. Аржников В.В., Громов М.С., Терехов И.В. Диагностика и мониторинг инфильтративных процессов в грудной полости с помощью люминесцентного излучения водосодержащих сред // Медицинский вестник МВД. 2009. № 2 (39). С. 40-46.

18. Терехов И.В., Петросян В.И., Никитина Е.Б. и др. Компьютерный анализ в ТРФ топографии для дифференциации и локализации очагов патологии в маммологии и пульмонологии // Миллиметровые волны в биологии и медицине. 2005. №1 (37). С. 56-66.

19. Терехов И.В., Парфенюк В.К. Мониторинг инфильтративных процессов нижних отделов респираторного тракта у пациентов с внебольничной пневмонией методом люминесцентного анализа в радиодиапазоне // Вестник восстановительной медицины. 2009. № 3. С. 46-50.

20. Громов М.С., Аржников В.В., Терехов И.В. Мониторинг воспалительного процесса при внебольничной пневмонии с помощью СВЧ-излучения органов грудной полости // Медицинский вестник МВД. 2010. № 5 (48). C. 16-17.

21. Громов М.С., Терехов И.В., Дзюба М.А., Аржников В.В. Использование активной резонансной СВЧ радиометрии для идентификации и мониторинга иммунно-воспалительных изменений у больных $c$ острыми инфильтративно-воспалительными процессами нижних отделов респираторного тракта // Вестник новых медицинских технологий. 2011. Т. 18. № 1. С. 38-41.

22. Громов М.С., Терехов И.В. Динамика иммунно-воспалительного ответа в его связи с интенсивностью СВЧ-излучения органов грудной полости при внебольничной пневмонии // Казанский медицинский журнал. 2010. T. 91. № 5. С. 611-614.

23. Громов М.С., Терехов И.В., Гладышев Ю.М. и др. Диагностика и оценка состояния процессов саногенеза у пациентов с инфекциями нижних дыхательных путей с помощью собственного радиоизлучения водосодержащих сред // Medline.ru. 2008. T. 9. № 1. C. 255-268.

24. Громов М.С., Терехов И.В. Функциональное состояние сердечно-сосудистой системы и водной компоненты внутренней среды организма при внебольничной пневмонии // Профилактическая и клиническая медищина. 2009. № 3. С. 82-84. 
25. Громов М.С., Аржников В.В., Терехов И.В. Возможности оценки функционального состояния организма с помощью собственного радиоизлучения нетепловой природы // Медицинский вестник МВД. 2008. № 5 (36). С. 38-43.

26. Терехов И.В., Логаткина А.В., Бондарь С.С. Функциональное состояние миокарда и его связь с состоянием водосодержащих сред органов грудной клетки при инфильтративных процессах в легких // Stredoevropsky Vestnik pro Vedu a Vyzkum. 2015. T. 51. C. 3.

27. Гаркави Л.Х., Квакина Е.Б. О критериях оценки неспецифической резистентности организма при действии различных биологически активных факторов с позищии теории адаптационных реакций // Миллиметровые волны в биологии и медицине. 1995. №6. С.11-21.

(C) 2015, Бондарь C.C.

Оценка уровня неспецифических адаптационных реакций методом активной радиометрии
(C) 2015, Bondar S.S.

Assessment of the level of nonspecific adaptive reactions method of active radiometry 